\title{
The influence of several aspects of verbal and pre-verbal communication of the teacher on the pupils
}

\author{
Gentjana Panxhi \\ Lecturer at the Faculty of Education \\ “Aleksandër Moisiu” Durrës University UAMD \\ E-mail: genta_panxhi@yahoo.com
}

Doi:10.5296/ ijhrs.v5i2.7424 URL: http://dx.doi.org/10.5296/ ijhrs.v5i2.7424

\begin{abstract}
As we know the main types of communication are the verbal, nonverbal and pre-verbal ones. According to several scholars the communication between the teacher and the pupils displays the fact that the density, the intensity, the quality, the space used by the both sides during the class exert a considerable influence in the creation of a general positive milieu in the classroom or in the relations between these two parties as well as the smooth continuation of the teaching and education process.

The communication at school being an important aspect of the school life serves to the proper development of the learning process on the part of the pupils and also based on human values serves as a general regulator in the relationship among the social groups in the micro environment at school.

We center our study on the character of the teacher with his contributions and modalities in his communication regarding the pupils, regarding the quality of the teaching in the close connection to the environment, the milieu being created in the classroom, also with his motivation in his academic work and his didactic efficiency. Our study aims to show the importance of several aspects of verbal and pre-verbal communication of the teacher and their perception by the pupils in Albanian schools.
\end{abstract}

Keywords: communication, tone, teacher, pupil, motivation 


\section{Introduction}

It is somehow difficult to offer a comprehensive, meaningful, functional and unique definition of the term communication. Different authors belonging to different schools and followers of different theories and disciplines offer and justify different definitions sometimes even contradictory ones. The term "communication" derives from the Latin word (Communis), which means "something common", thus asking for all the parties involved to understand a common language in order to exchange messages with one another.

The communication is the process of sending and receiving messages and it contains two or more persons and at least one of them wants to communicate. When we communicate we help ourselves in increasing our common knowledge i.e. our " common sense", which is an essential precondition for the existence of every community. ${ }^{1}$

According to E. Cheli the communication is one of the essential dimensions of the social life and activities of the human being and in a figurative way can be considered as a binding string of the society itself ${ }^{2}$. In the framework of the teaching process the communication between the two parties (teachers \& pupils) is the very heart of such a process as is defined by L.B. Rosenfeld. It is very difficult to find another professional activity, where human communication weighs so much as in the field of the education. ${ }^{3}$

In this frame work several elements, as we treat further on, receive quite an importance which at first glance seem not to be connected with such a process.

The most importance means of the communication of the teacher to the pupils is precisely his voice, his speech. The teacher should understand that the verbal communication is composed of not only words and phrases but also of rhythm, the speed of expression, the tone of the voice, pauses, the distances between the words, all these have their own importance in such a process.

The volume of the voice, the speed of expression and the rhythm are the vocal components of the language and as such they play an important role in it.

A high volume of voice transmits conveys assurance and enthusiasm, while a low volume often conveys the contrary.

\section{Methodology}

We organized this survey using a questionnaire in order to identify the opinion of the pupils and the teachers of the secondary schools in connection with the verbal communication and several elements of the pre-verbal communication. We aimed also at defining how communication serves as an everyday means in an efficient fulfillment of the teaching

\footnotetext{
${ }^{1}$ Karl Erik Rosengren, Introduzione allo studio della comunicazione, Società editrice il Mulino, Bologna. 2001

${ }^{2}$ E. Cheli, Teorie e tecniche della comunicazione interpersonale. Un'introduzione interdisciplinare, Franco Angeli, Milano 2004.

${ }^{3}$ L.B. Rosenfeld e J.M. Richman,(1999) "Supportive communication and school outcomes, part II: Academically "at-risk" low income high school students", COMMUN EDUC, 48(4),
} 
process and also in harmonizing such a common process.

We undertook field work in the form of a survey among the secondary school pupils in several of the biggest towns of Albania, where there is the majority of the public and private schools and interviewing pupils of all the grades (from 10 to 12 grades) in these schools. This survey served us to achieve the targets of our study in order to collect the opinions of the pupils on their reciprocal communications.

We chose 1050 pupils the right number for our sample. We made a random selection of the pupils of our sample. They belong to both sexes and different ages and schools so that our sample became as representative as possible.

The methodology applied in our study is chosen in order to suit best to the fulfillment of our target. Our methodology is a happy combination of primary and secondary data. The secondary data come from the study of a vast and up to date literature covering the communication in general and the communication between the teacher and the pupils in particular. The sources of the literature consulted in our study are different ones such as similar studies in neighboring countries and in our region as well as other sources which served us to enrich the theoretical background of our study.

One of the strategies used in our study is the application of the questionnaire and the observations collected thanks to such questionnaires. The application of the strategy of the observation makes possible the collection of data and the quantitative analyses of such data applying descriptive and analytical statistics. The data collected by applying such a strategy can also be used to suggest possible reasoning on certain relations among the variables as well as to establish models of such relations.

We have applied several methods in order to meet the targets of our study taking into account simultaneously their advantages and disadvantages. The application of the questionnaires as a method to gather data for our study enables not only the analyses of the possible relations among the variables treated in our study, but also it creates the possibility to offer several recommendations on the quality of the communication during the teaching process.

Khandwalla (1976) believed that there is no scientific method to be considered as the best one. ${ }^{4}$

Our questionnaire is made of 2 parts

The first sections offer information on the sex, age, grade, the type of school (private or public) of the pupils. Their average mark (grade) and their learning level (stage).

The second section covers the verbal communication and several characteristics of the pre-verbal communication of the teachers towards the pupils, evaluating their answers by applying the Likert Scale (- strongly disagree to strongly agree) covering such topics as the

\footnotetext{
${ }^{4}$ Khandwalla, P. (1977). "Some top management styles, their content and performance". Organization and Administrative Sciences, 7: 21-51.
} 


\section{Macrothink}

International Journal of Human Resource Studies

ISSN 2162-3058

2015, Vol. 5, No. 2

application of incentive words used by the teacher, the rhythm of the communication or a teacher speaking in a dialect not the literary language.

First we carried out a pilot test of the questionnaire. We tested the questionnaire among 70 pupils, selected at random in order to check whether there were misunderstandings, or problems in filling in the questionnaire as well as testing its validity and reliability. The results of the pilot test demonstrated that the questions of the questionnaire were well defined and easily understood ones.

\section{Analyses of the findings regarding the pupils}

The final analyses of our field work covered 1050 pupils (questioned) living in some of the large towns in Albania and studying in public and private schools. The data displayed on Table 1 show that the Capital Tirana occupies more than half of the pupils some 51,9\%, because Tirana makes up for some 1/3 of the population of Albania thus the largest amount of pupils studying in public and private schools. The second comes the town of Durres with some $19,9 \%$ of the total number of pupils in question followed by the towns of Shkodra and Vlora with respectively $15,8 \%$ and $12,4 \%$ of the total number of pupils answering our questionnaire.

Table 1 The distribution of pupils according to the towns

\begin{tabular}{|l|l|l|}
\hline Town & Frequency & Percentage \\
\hline Durrës & 209 & 19.9 \\
\hline Shkodër & 166 & 15.8 \\
\hline Tiranë & 545 & 51.9 \\
\hline Vlorë & 130 & 12.4 \\
\hline Total & 1050 & 100.0 \\
\hline
\end{tabular}

The distribution of the pupils according to the type of school they attend the graphic 1 shows that $81 \%$ of them attend public schools and the rest attend private ones. Such a ratio is a normal one as the majority of the pupils attend public schools though we witness an increase in the number of pupils attending private schools in the 9 grades schools and in secondary schools (10 to 12 grades) in the recent years. 


\section{Macrothink}

International Journal of Human Resource Studies

ISSN 2162-3058

2015, Vol. 5, No. 2

Graphic 1 The pupils distribution according to the type of school they attend.

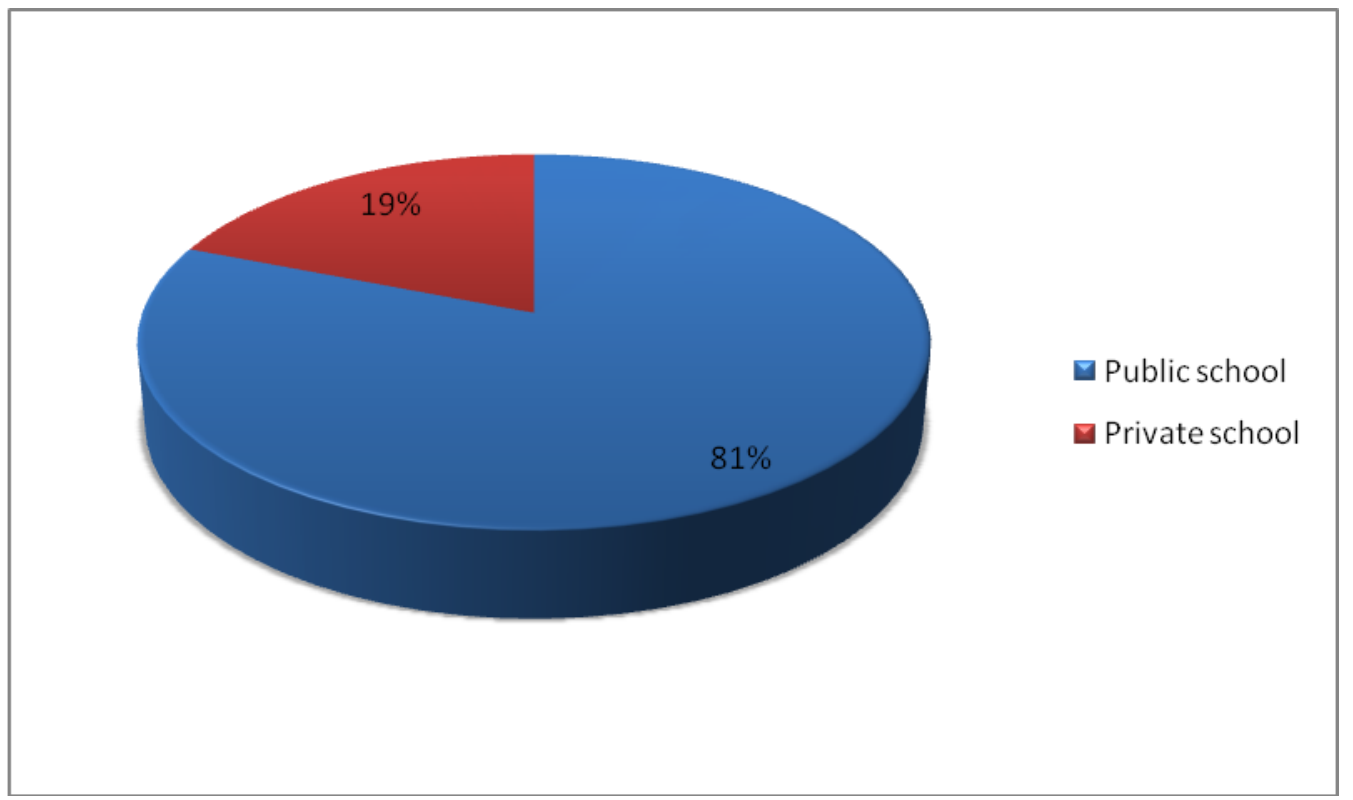

The next graphics shows that $55,5 \%$ of the pupils are females and $44,5 \%$ are males thus reflecting the national ratio of female and male pupils

Graphic 2 Sex

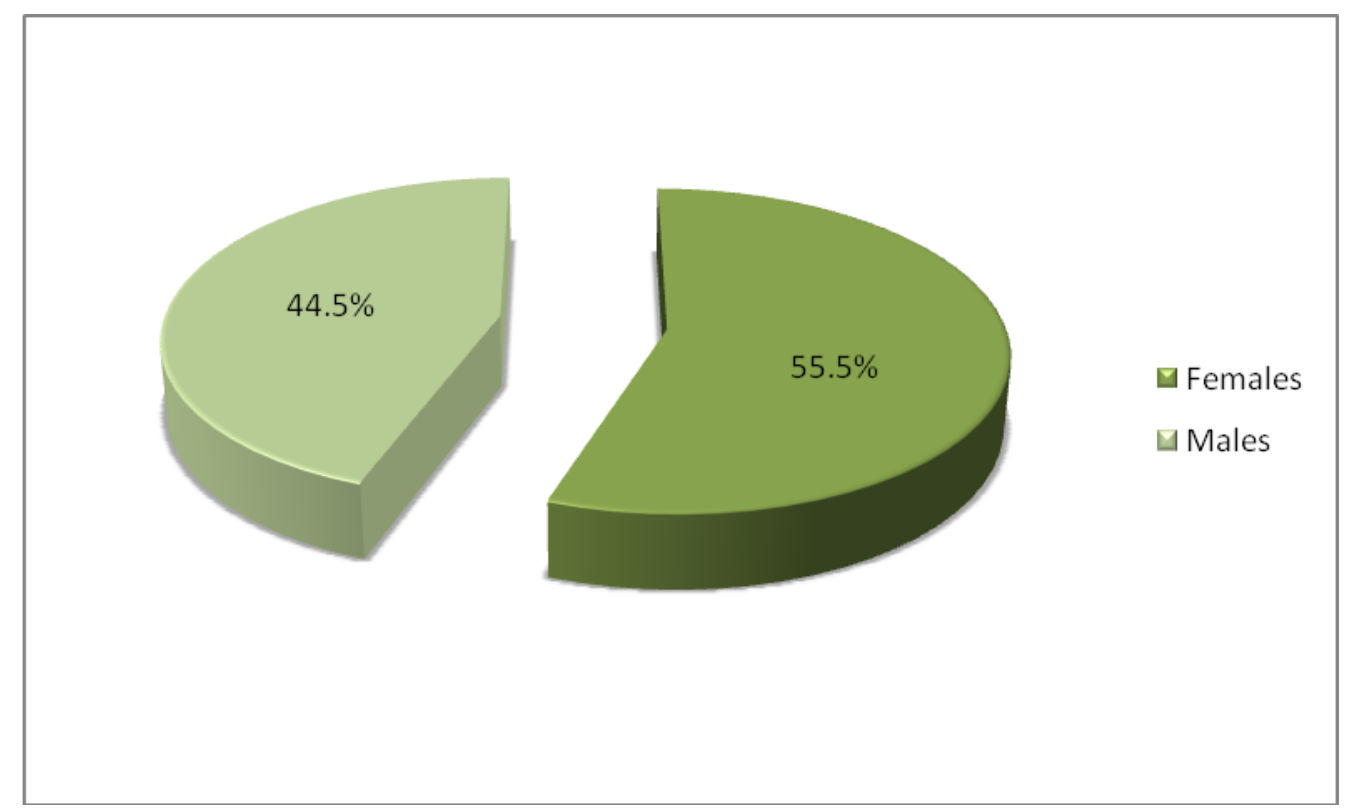

The interviewed pupils belong to the age group 16,5 years old (the average age) ranging from 15 to 20 years old, as our study covered the vocational schools (four years of study ones), as well.

The distribution according to the grades 9forms) is as follows: 38,9\% belong to the $\mathrm{X}$ grade, then $37,1 \%$ of the total of the pupils belong to the Xi followed by XII and XIII having 
respectively $20,6 \%$ and $3,6 \%$ of the pupils. (table 2 )

Table 2 The distribution of the pupils according to the grades

\begin{tabular}{|l|l|l|}
\hline Class & Frequency & Percentage \\
\hline Class X & 408 & 38.9 \\
\hline Class XI & 390 & 37.1 \\
\hline Class XII & 214 & 20.4 \\
\hline Class XII & 38 & 3.6 \\
\hline Total & 1050 & 100.0 \\
\hline
\end{tabular}

The pupils were asked about their learning level (the marks they receive). More than half of them some $50,3 \%$ of them declared a medium level, some $28,5 \%$ declared a high level and $12,4 \%$ declared a top level, while $7,4 \%$ of them were low level and $1,4 \%$ rated very low level (Graphics 3). The pupils declaring a low or very low level predominantly belong to public schools respectively $91,6 \%$ and $93,3 \%$ of them.

Graphics 3 The evaluation of the learning level

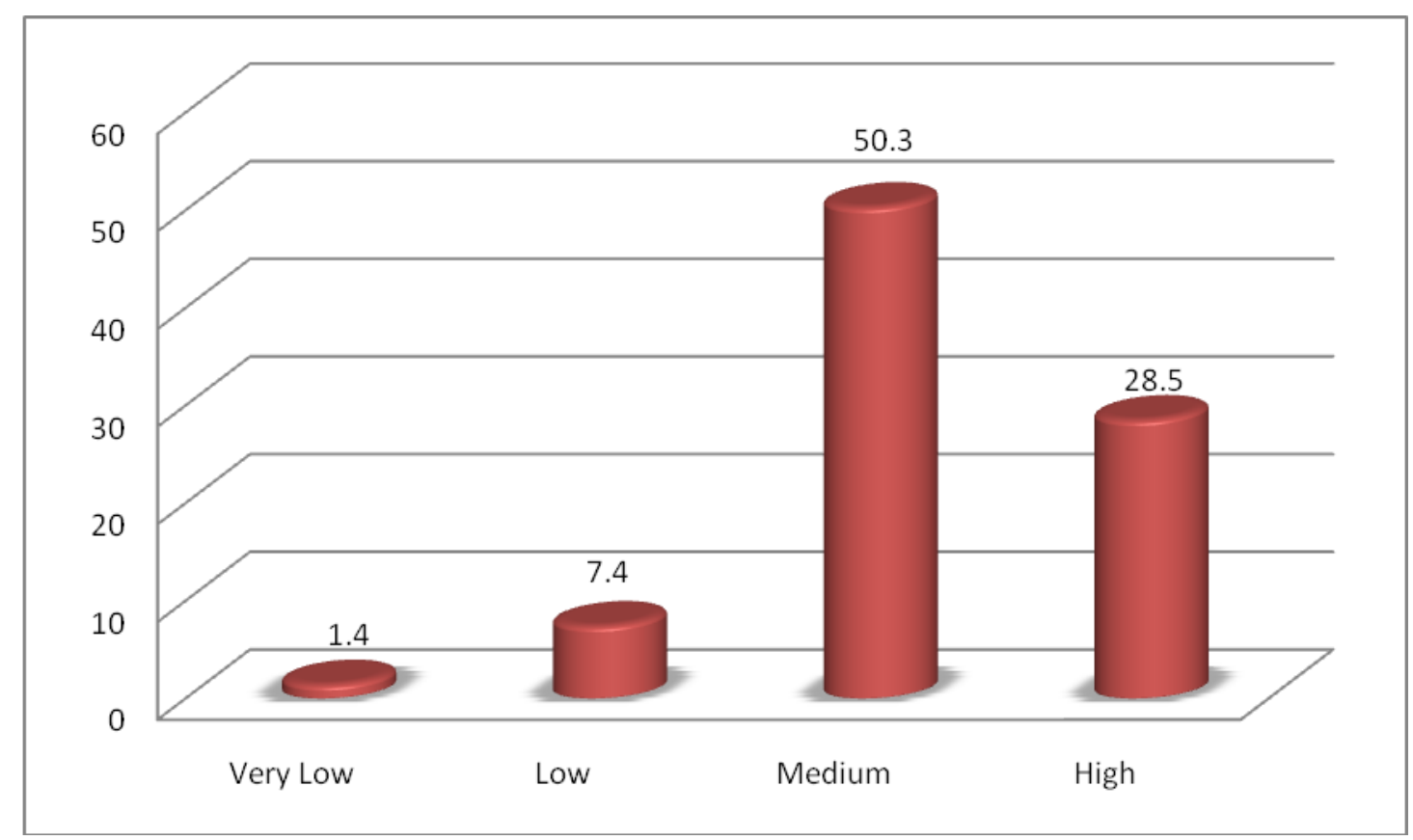

Judging by the date of that table we observe that the average mark declared by the pupils of 
our sample is 8,1 and the lowest mark is 4,5 while the highest one is 10 .

The sample pupils answered to the questions covering the verbal communication and some characteristics of the pre-verbal communication as follows:

Question: Are you better motivated when the teacher uses encouraging words during the explanation of the lesson? Some $40,3 \%$ of them agree, some $25,7 \%$ of them fully agree and $23,5 \%$ of them disagree or strongly disagree, the rest remain neutral thus they do not consider the usage of encouraging words as a motivating element.

Question: When the teacher is unable to select the right words while explaining the lesson do you understand the lesson? Some $62,2 \%$ agree or fully agrre, $8,8 \%$ are neutral and the rest disagree that the correct selection of the words on the part of the teacher is the key to the good understanding of the lesson.

Question: When the teacher uses dialect instead of the literary language is it more difficult to understand the lesson? Some $56,4 \%$ of the pupils say yes, thus the usage of a dialect y the teacher makes the lesson more difficult to be understood, while $11 \%$ of the pupils are neutral and $31,6 \%$ i.e. almost one third of them the communication in dialect offers no difficulty to them, a sin big cities especially in Tirana the pupils come from an area when a certain dialect is the overwhelming one thus creating them no problem in understanding it.

Question: Are the words selected by the teacher during the teaching process not very important, as it is enough that they convey the message and that's it? Some $48 \%$ of the pupils agree or fully agree and $46 \%$ disagree the rest are neutral.

The affirmation that: If the teacher is not prolific during the explanation of the lesson I do not fully understand the lesson is true for some $62,8 \%$ of the pupils, who are very attentive during the explanation of the lesson especially the new knowledge or special problems of the lesson. Some $24,3 \%$ of the pupils find no fault with the teacher being not prolific during the explanation and the rest of them some $12,8 \%$ are neutral.

Question: Is it difficult for you to learn a certain subject if the teacher continuously raises the voice (uses a pitch voice) during the class? Some 21,4\% answer: no problem at all. Of course most of them are used to such a method of teaching or display poor results in the class. Some 67,15 of the pupils consider the raised voice of the teacher during the class as worrisome and resulting in more difficulties in understanding the lesson. The rest of the pupils are neutral. Of course we already know thanks to our own practice or from the results obtained from various studies that the proper communication often is the key of the success in the teachers-pupils relations. Quite often we have been informed that some pupils can not assimilate the lesson only because of the manners manifested by their teacher in the classroom.

Question: Does a teacher speaking in a soft and calm voice motivate me more during the class? More than $3 / 4$ or some $76,7 \%$ of the pupils confirm it. Thus a such a daily communication not only calms down the pupils but also motivates them to learn more. Some $12,5 \%$ of the pupils disagree and $10,8 \%$ are neutral. 


\section{Macrothink}

The rhythm of the communication is another important element in the day to day teacher-pupils communication. Question: Do you lose the interest in the lesson when the teacher speaks at the same rhythm (monotonous voice)? Some 37,9\% of the pupils agree, while some $43,9 \%$ disagree. 191 pupils .e. $18,2 \%$ of the total number of the pupils are neutral.

\section{Conclusions}

We can conclude that the volume of the voice, its speed and rhythm not only constitute a very important sonar component of the language, but they also play a very important role in the communication in general.

A high volume of voice imparts (transmits) assurance and enthusiasm, while a low volume transmits the contrary. A good lecture during most of it is in need of a relative high volume of the voice but not necessary reaching a scream level. This is especially important to the pupils seated in the last rows of the benches as they may not be able to listen the voice of the teacher especially when audio aids are missing. A high voice makes forces the teacher into being a dynamic and active one. The lower the voice is the more static and passive will be the class.

A low volume of voice should be used somehow more rarely. It is necessary when we want to adopt a well wishing and appreciating attitude towards the pupil for instance when we answer to a question raised by a pupil when he expresses his difficulty in understanding something in the explanation of the teacher.

A good volume of the voice and a well balanced speed of the voice favor a change in the rhythm thus helping the teacher in not being monotonous during the class. A more than necessary stressing of the words on the part of the teacher risks in turning of the class into an open-air meeting. A continuous stressing of the words and phrases slows down the speech and the rhythm thus falling into monotony and annoying the audience i.e. the pupils. The teacher should also use during the lesson as best as he can the literary standard of the Albanian language.

1. Anolli, L. (2002). Psicologia della comunicazione. Bologna: il Mulino

2. E. Cheli, Teorie e tecniche della comunicazione interpersonale. Un'introduzione interdisciplinare, Franco Angeli, Milano 2004.

3. Ekman. P., Friesen, W. V. (1986). A new pan-cultural facial expression of emotion. Motivation and Emotion, 10,159-168.

4. Elliot, A. J., \& Dweck, C. S. (Eds.). (2005). Handbook of competence and motivation. New York, NY: Guilford Press.

5. Jakobson, R (1966) Saggi di linguistica generale, Feltrinelli

6. Karl Erik Rosengren, Introduzione allo studio della comunicazione, Società editrice il Mulino, Bologna. 2001

7. Kendon, A. (1995). Gestures as illocutionary and discourse structure markers in 


\section{Macrothink \\ International Journal of Human Resource Studies \\ ISSN 2162-3058 2015, Vol. 5, No. 2}

Southern Italian conversation. Journal of Pragmatics, 23, 247-279

8. Khandwalla, P. (1977). "Some top management styles, their content and performance". Organization and Administrative Sciences, 7: 21-51.

9. L.B. Rosenfeld e J.M. Richman,(1999) "Supportive communication and school outcomes, part II: Academically "at-risk" low income high school students", COMMUN EDUC, 48(4),

10. Mastronardi, V. (1998). Le strategie della comunicazione umana. Milano: Franco Angeli

11. McLuhan, M. (1986), Gli strumenti del comunicare, Garzanti, Milano.

12. Mehrabian, A. (1972). Nonverbal communication, Chicago-New York: Aldine-Atheron.

13. R. MUCHIELLI, Communication e resaux de communications. E.S.F. Paris 1991

14. Raimondo. G (1978) Comunicazione e linguaggi Firenze : Le Monnier

15. Shaw. M.(1964) Comunication networks, L. Berkowitz, Advances in experimental psychology. New York: Academic Press

16. Zimmerman, B. J. (2001). Self-regulated learning and academic achievement theoretical perspectives. B. J. Zimmerman., \& D. H. Schunk, Theories of selfregulated learning and academic achievement: An overview and analysis ( $2^{\text {nd }}$ ed.). Mahwah, NJ: Lawrence Erlbaum Associates 